\title{
Agreement between heart rate at first ventilatory threshold on treadmill and at 6-min walk test in coronary artery disease patients on $\beta$-blockers treatment
}

\author{
Leonardo Calegarii,*, Igor Moreira², Andrei Falkowski², José Basileu Caon Reolão ${ }^{3}$, Marlus Karsten $^{4,5,6}$, Luís Fernando Deresz ${ }^{7,9,9}$ \\ 'Physical Therapy Department, Faculdade Especializada da Área da Saúde do Rio Grande do Sul (FASURGS), Passo Fundo, RS, Brazil \\ ${ }^{2}$ Physical Therapy Department, Universidade de Passo Fundo (UPF), Passo Fundo, RS, Brazil \\ ${ }^{3}$ Medicine College, Universidade de Passo Fundo (UPF), Passo Fundo, RS, Brazil \\ ${ }^{4}$ Departamento de Fisioterapia, Universidade do Estado de Santa Catarina (UDESC), Florianópolis, Brazil \\ ${ }^{5}$ Graduate Program in Physical Therapy, Universidade do Estado de Santa Catarina (UDESC), Florianópolis, Brazil \\ ${ }^{6}$ Graduate Program in Rehabilitation Sciences, Universidade Federal de Ciências da Saúde de Porto Alegre (UFCSPA), Porto Alegre, Brazil \\ ${ }^{7}$ Physical Education Department, Health Sciences Institute, Universidade Federal de Juiz de Fora, Governador Valadares, Brazil \\ ${ }^{8}$ Post Graduation Program in Health Applied Sciences, Universidade Federal de Juiz de Fora, Campus Governador Valadares, MG, Brazil \\ ${ }^{9}$ Research Group Ciência, Saúde e Desempenho Físico, Universidade Federal de Juiz de Fora, Campus Governador Valadares, MG, Brazil
}

The purpose of this study was to verify the accuracy of the agreement between heart rate at the first ventilatory threshold (HRvit) and heart rate at the end of the 6 -min walk test (HRoww) in coronary artery disease (CAD) patients on $\beta$-blockers treatment. This was a cross-sectional study with stable CAD patients, which performed a cardiopulmonary exercise test (CPET) on a treadmill and a 6 -min walk test (6MWT) on nonconsecutive days. The accuracy of agreement between $\mathrm{HR}_{\mathrm{VT}}$ and $H R_{6 \mathrm{GW}}$ was evaluated by Bland-Altman analysis and Lin's concordance correlation coefficient $\left(\mathrm{r}_{\mathrm{c}}\right)$, mean absolute percentage error (MAPE), and standard error of estimate (SEE). Seventeen stable CAD patients on $\beta$-blockers treatment (male, $64.7 \%$; age, $61 \pm 10$ years) were included in data analysis. The Bland-Altman analysis revealed a negative bias of $-0.41 \pm 6.4 \mathrm{bpm}(95 \%$ limits of agreements, -13 to $12.2 \mathrm{bpm}$ ) between
$H R_{v 11}$ and $H R_{6 m w r}$. There was acceptable agreement between $H R_{v 11}$ and HR $R_{\text {GMw }}\left(r_{c}=0.84 ; 95 \%\right.$ confidence interval, 0.63 to 0.93 ; study power analysis $=0.79$ ). The MAPE of the HRoww was $5.1 \%$ and SEE was $6.6 \mathrm{bpm}$. The ratio $H R_{v 1} / \mathrm{HR}_{\text {peak }}$ and $\mathrm{HR}_{\text {gww }} / \mathrm{HR}_{\text {peak }}$ from CPET were not significantly different $(81 \% \pm 5 \%$ vs. $81 \% \pm 6 \%, P=0.85)$; respectively. There was a high correlation between $H R_{v 11}$ and $H_{6 w w 1}(r=0.85, P<0.0001)$. Finally, the results of the present study demonstrate that there was an acceptable agreement between $\mathrm{HR}_{\mathrm{vT}}$ and $\mathrm{HR}_{6 \mathrm{WW}}$ in $\mathrm{CAD}$ patients on $\beta$-blockers treatment and suggest that HRøмw may be useful to prescribe and control aerobic exercise intensity in cardiac rehabilitation programs.

Keywords: Heart rate, Ventilatory threshold, 6-Minute walk test, Cardiac rehabilitation, Coronary artery disease

\section{INTRODUCTION}

Cardiovascular diseases are the predominant cause of death worldwide and coronary artery disease $(\mathrm{CAD})$ is the most common type of heart disease, accounting for $42.6 \%$ of all deaths in the United States of America (Virani et al., 2020). An essential component of contemporary care for patients with $\mathrm{CAD}$ is the promotion of a healthy lifestyle and control of cardiovascular risk factors (Knuuti et al., 2020). Exercise-based cardiac rehabilitation programs promote a reduction in mortality rates, decrease the risk of rehospitalization, and improve the quality of life of patients with CAD (Anderson et al., 2016; Dunlay et al., 2014). In cardiac patients, regular practice of supervised physical exercise requires an individualized prescription to optimize exercise benefits and minimize risks, offering greater safety during training (Carvalho et al., 2020; Fletcher et al., 2013).
${ }^{*}$ Corresponding author: Leonardo Calegari (iD) https://orcid.org/0000-0003-0758-3467 Physical Therapy Department, Faculdade Especializada da Área da Saúde do Rio Grande do Sul, Angélica Otto, 160, Boqueirão, Passo Fundo, RS, 99025-270, Brazil Email: profcalega@gmail.com

Received: August 16, 2021 / Accepted: September 17, 2021
This is an Open Access article distributed under the terms of the Creative Commons Attribution Non-Commercial License (https://creativecommons.org/licenses/by-nc/4.0/) which permits unrestricted non-commercial use, distribution, and reproduction in any medium, provided the original work is properly cited. 
In $\mathrm{CAD}$ patients undergoing cardiac rehabilitation, the recommended aerobic exercise intensity is close to the first ventilatory threshold ( $\mathrm{VT}_{1}$ ) (Pymer et al., 2020; Tabet et al., 2008; Tan et al., 2017). The $\mathrm{VT}_{1}$ represents the exercise intensity corresponding to the transition from purely aerobic metabolism to a point where blood lactate begins to rise in the blood but reaches equilibrium (as a result of progressive activation of anaerobic glycolysis, with stable lactate levels of $1.5-2 \mathrm{mmol} / \mathrm{L}$ due to an equal lactate rate of appearance vs. rate of disappearance) (Hansen et al., 2021). Regular exercises with intensity equivalent to $\mathrm{VT}_{1}$ is medically safe (Chaloupka et al., 2005; Tabet et al., 2008), precede the ischemic threshold (Bussotti et al., 2006), elicit significant physiological adaptations (Prado et al., 2016) and clinical benefits (Zheng et al., 2008). However, the use of a cardiopulmonary exercise test (CPET), necessary to $\mathrm{VT}_{1}$ definition, involves high costs which limit its practical application in most cardiovascular rehabilitation services, mainly in low to middle-income countries. Furthermore, it is known that fewer patients are undergoing a CPET at the entry to cardiac rehabilitation (Brubaker et al., 2018; Hansen et al., 2021).

Studies have been investigating alternatives ways to prescribing aerobic exercise in heart diseases patients (Casillas et al., 2013; Casillas et al., 2017; Oliveira et al., 2016). The 6-min walk test (6MWT) is a well-established method of assessing physical capacity, practical, simple, and low-cost test, used in cardiovascular rehabilitation programs (Bellet et al., 2012; Casillas et al., 2013). Despite the well-known value of the 6MWT to predict cardiorespiratory fitness, little is known about exercise prescription intensity based on 6MWT heart rate ( $\left.\mathrm{HR}_{6 \mathrm{MWT}}\right)$ in CAD patients on $\beta$-blockers treatment (Casillas et al., 2017).

Gayda et al. (2004) showed that $\mathrm{VO}_{2}$ and heart rate values at the end of 6MWT did not differ from those values obtained during $\mathrm{CPET}$ at $\mathrm{VT}_{1}$. However, in this study, some CAD patients were not on $\beta$-blockers treatment. Furthermore, the accuracy of the agreement between $\mathrm{HR}_{6 \mathrm{Mw}}$ and heart rate at $\mathrm{VT}_{1}\left(\mathrm{HR}_{\mathrm{VT} 1}\right)$, important for use as a real clinical practice exercise control parameter, was not yet reported. Thus, the purpose of this study was to evaluate the accuracy of the agreement between $\mathrm{HR}_{\mathrm{VT} 1}$ and $\mathrm{HR}_{6 \mathrm{MWT}}$ in CAD patients on $\beta$-blockers treatment. Our hypothesis is that is an acceptable agreement between heart rate from 6MWT and CPET in CAD patients on $\beta$-blockers treatment and that $\mathrm{HR}_{6 \mathrm{MWT}}$ may be useful to prescribe aerobic exercise in cardiac rehabilitation programs.

\section{MATERIALS AND METHODS}

\section{Participants}

Seventeen patients with CAD under $\beta$-blockers treatment were recruited from the institutional phase II cardiovascular rehabilitation program. All participants met at least three inclusion criteria, such as acute myocardial infarction (MI), coronary artery bypass grafting $(\mathrm{CABG})$, percutaneous coronary intervention (PCI), obesity, and type 2 diabetes mellitus. Exclusion criteria were diagnosis of atrial fibrillation, hemodynamic instability, ventricular arrhythmias, and respiratory, neurological, or musculoskeletal disease. In addition, patients who failed to achieve a maximum respiratory exchange ratio $(>1.05)$ in the CPET were excluded from the analysis (Keteyian et al., 2010). All individuals provided informed written consent, and the study protocol was approved by the University of Passo Fundo institutional research ethics committee (\#363/10).

\section{Experimental procedure}

Patients were undergone a CPET and after 48 hours to two 6MWTs. The CPET was performed on a treadmill (Master ATL, Inbramed, Porto Alegre, Rio Grande do Sul, Brazil) in a controlled temperature $\left(21^{\circ} \mathrm{C}-23^{\circ} \mathrm{C}\right)$ laboratory. Individuals were continuously monitored in electrocardiographic derivations, using the ramp protocol with analysis of expired gases $\left(\mathrm{O}_{2}\right.$ and $\left.\mathrm{CO}_{2}\right)$ in open circuits (Ergo PC Elite software, Micromed, Brasilia, Brazil) (Fletcher et al., 2013). At the beginning of each CPET day, an auto-calibration was performed according to the manufacturer's instructions. A medium-flow pneumotachograph (10 to 120 liters/ $\mathrm{min}$ ) was used and measurements were collected in fixed time every $20 \mathrm{sec}$ (VO2000, Aerosport MedGraphics, Saint Paul, MN, USA). The $\mathrm{VT}_{1}$ was determined by the ventilatory technique identifying the lower points of the oxygen ventilatory equivalent $\left(\mathrm{VE} / \mathrm{VO}_{2}\right)$ and the expired fraction of $\mathrm{O}_{2}$ before these values began to rise, while the ventilatory equivalent of carbon dioxide (VE/ $\mathrm{VCO}_{2}$ ) and the expired $\mathrm{CO}_{2}$ fraction remained stable (Mezzani et al., 2009). The highest oxygen uptake observed in the last $40 \mathrm{sec}$ of the exercise was defined as $\mathrm{VO}_{\text {2peak }}$ (Fletcher et al., 2013). The heart rate at the first ventilatory threshold $\left(\mathrm{HR}_{\mathrm{VT} 1}\right)$ was calculated as the average of $40 \mathrm{sec}$ and heart rate response at the first ventilatory threshold $\left(\mathrm{HRR}_{\mathrm{VT1}}\right)$ was calculated as $\mathrm{HR}_{\mathrm{VT} 1}$ minus $\mathrm{HR}$ at rest. The age-predicted maximal HR was derived from the prediction equations $\mathrm{HR}_{\max }=(208-0.7 \times$ age $)$ in men and $\mathrm{HR}_{\max }=$ (206-0.88 ×age) in women (Fletcher et al., 2013). In addition, we evaluated the HR response to incremental CPET. 
The 6MWT was performed following the guidelines established by the European Respiratory Society/American Thoracic Society by trained evaluators (Holland et al., 2014). Patients walked as far as possible for six minutes in a 30-m-long flat lane, with standardized incentives. Two tests were performed with an interval of $60 \mathrm{~min}$ and the longest covered distance test was used for analysis (Bellet et al., 2012; Holland et al., 2014). During the 6MWT, all patients used the HR monitor (Polar S810i, Polar Electro Oy, Kempele, Finland) that continuously showed the HR throughout the 6-min test. The highest value of the HR was noted during the last 30 sec of the 6MWT ( HR $_{6 \mathrm{MWT}}$ ) (Morard et al., 2015). Resting HR was assessed while the patients were standing for $60 \mathrm{sec}$, after a 5-min rest sitting. The $\mathrm{HR}_{6 \mathrm{MWT}}$ was used to assess the relative intensity of the 6MWT to the maximal HR from CEPT. Heart rate response at the end of the 6MWT (HRR ${ }_{\text {omwT }}$ ) was calculated as $\mathrm{HR}_{6 \mathrm{MwT}}$ minus $\mathrm{HR}$ at rest. The predicted distance was calculated using the formula (equation 1) proposed by (Britto et al., 2013). All tests were performed between 8:00 and 11:00 a.m., at the same place, and followed the same protocol.

\section{Statistical analysis}

Data distribution was evaluated by the Shapiro-Wilk test and expressed in mean, standard deviation (SD), and qualitative variables by frequency distribution. Comparisons between $\mathrm{HR}_{\mathrm{VT1}}$ and HR $_{\text {омwт }}$ were performed by paired $t$-test. Pearson correlation and Bland-Altman analyses were used to evaluate the association and agreement between $\mathrm{HR}_{\mathrm{VT1}}$ and $\mathrm{HR}_{6 \mathrm{MWT}}$, respectively (Bland and Altman, 1986). Limits of agreement were calculated (mean bias \pm $\mathrm{SD} \times 1.96)$ for each Bland-Altman assessment. Mean absolute percentage error (MAPE) $\left[\left(\mathrm{HR}_{V \mathrm{VT} 1}-\mathrm{HR}_{6 \mathrm{MWT}}\right) / \mathrm{HR}_{\mathrm{VT} 1} \times 100\right]$ provided a general measurement error for $\mathrm{HR}_{6 \mathrm{MWT}}$. In addition, the accuracy of agreement between $\mathrm{HR}_{\mathrm{VT1}}$ and $\mathrm{HR}_{6 \mathrm{MWT}}$ was evaluated by Lin concordance correlation coefficient $\left(\mathrm{r}_{\mathrm{c}}\right)(\mathrm{Lin}, 1989)$ and by the standard error of estimate (SEE) (Sarzynski et al., 2013). We

Table 1. Patients' clinical characteristics $(n=17)$

\begin{tabular}{lc}
\hline Characteristic & Value \\
\hline Sex, men:women & $11: 6$ \\
Age $(\mathrm{yr})$ & $61 \pm 10$ \\
Body mass index $\left(\mathrm{kg} / \mathrm{m}^{2}\right)$ & $29.8 \pm 5$ \\
Diabetes mellitus & $9(52.9)$ \\
Hypertension & $11(64.7)$ \\
Obesity & $9(52.9)$ \\
Hyperlipidemia & $12(70.5)$ \\
\hline
\end{tabular}

Values are presented as mean \pm standard deviation or number (\%). considered an acceptable accuracy of agreement when $r_{c}>0.8$ (Gillinov et al., 2017), MAPE within 5\% (Navalta et al., 2020) and SEE $\leq 7 \mathrm{bpm}$ (Oliveira et al., 2016). $P$ values $<0.05$ were considered significant. Data were analyzed using GraphPad Prism 6 (GraphPad Software, La Jolla, CA, USA) and IBM SPSS Statistics ver. 19.0 (IBM Co., Armonk, NY, USA). Lin concordance correlation coefficient study power analysis was calculated using Power Analysis \& Sample Size 2021 (NCSS, LLC, Kaysville, UT, USA). This statistical test uses a one-sided $z$-test with a 0.15 significance level.

\section{RESULTS}

Seventeen patients ( $64.7 \%$ men), $61 \pm 10$ years old, and $29 \pm$ $5 \mathrm{~kg} / \mathrm{m}^{2}$ of body mass index were included in the study. Most patients had a diagnosis of MI with primary (53\%) or elective (23.5\%) PCI, CABG (23.5\%), and all patients were under optimal medical treatment. Twelve patients used selective $\beta 1$-adrenergic receptor antagonists $(54 \pm 23 \mathrm{mg} / \mathrm{day})$; four patients used the third generation of $\beta$-blockers with vasodilatory effect $(15 \pm 6 \mathrm{mg} /$ day $)$ and

Table 2. Cardiopulmonary exercise test and 6-min walk test (6MWT) results $(n=17)$

\begin{tabular}{|c|c|}
\hline Variable & Value \\
\hline \multicolumn{2}{|l|}{ Cardiopulmonary exercise test } \\
\hline $\mathrm{VO}_{2 \text { peak }}(\mathrm{mL} / \mathrm{kg} / \mathrm{min})$ & $21.5 \pm 5$ \\
\hline $\mathrm{VO}_{2 \mathrm{~V} 11}(\mathrm{~mL} / \mathrm{kg} / \mathrm{min})$ & $15.4 \pm 3.2$ \\
\hline $\mathrm{VO}_{2 \mathrm{~V} 1} / \mathrm{NO}_{2 \text { peak }}(\%)$ & $74 \pm 7$ \\
\hline $\mathrm{HR}_{\text {rest }}(\mathrm{bpm})$ & $70 \pm 9$ \\
\hline HRVI1 (bpm) & $103 \pm 10$ \\
\hline $\mathrm{HR}_{\text {peak }}(\mathrm{bpm})$ & $127 \pm 16$ \\
\hline $\mathrm{HRR}_{\mathrm{vT1}}(\mathrm{bpm})$ & $31 \pm 11$ \\
\hline $\mathrm{HRR}_{\text {peak }}(\mathrm{bpm})$ & $56 \pm 14$ \\
\hline pMHR (bpm) & $159 \pm 11$ \\
\hline $\mathrm{HR}_{\mathrm{V} T 1} / \mathrm{HR}_{\text {peak }}(\%)$ & $81 \pm 5$ \\
\hline $\mathrm{RER}_{\text {peak }}$ & $1.13 \pm 0.09$ \\
\hline \multicolumn{2}{|l|}{ 6-Min walk test } \\
\hline Covered distance (m) & $501 \pm 109$ \\
\hline Covered distance/predicted (\%) & $92 \pm 18$ \\
\hline$H R_{\text {rest }}(b p m)$ & $72 \pm 7$ \\
\hline $\mathrm{HR}_{6 \mathrm{MWT}}$ (bpm) & $103 \pm 12$ \\
\hline HRR $_{6 \mathrm{MWT}}(\mathrm{bpm})$ & $30 \pm 8$ \\
\hline HRвмwт/HR $/ R_{\text {peak }}$ CPET (\%) & $81 \pm 6$ \\
\hline
\end{tabular}

Values are presented as mean \pm standard deviation.

$\mathrm{VO}_{2}$, oxygen uptake; $\mathrm{HR}$, heart rate; $\mathrm{HR}_{\text {rest, }} \mathrm{HR}$ at rest; $\mathrm{HR}_{\text {peak, }}$, maximum $\mathrm{HR}$; $\mathrm{pMHR}$, age-predicted maximal $\mathrm{HR}$; $\mathrm{VT}_{1}$, first ventilatory threshold; $\mathrm{HRR}$, heart rate response; RER, respiratory exchange ratio; CPET, cardiopulmonary exercise test. 
one patient used propranolol (160 mg/day). Additional patients' clinical characteristics are shown in Table 1.

Table 2 shows the CPET and the 6MWT results. All patients performed both tests without complications. No statistically significant differences were found between $\mathrm{HR}_{\mathrm{VT1}}$ and $\mathrm{HR}_{6 \mathrm{MWT}}(103.2 \pm$ $10.8 \mathrm{bpm}$ vs. $103.6 \pm 12.3 \mathrm{bpm}, P=0.81$ ). When expressed in percentage of CPET $\mathrm{HR}_{\max }, \mathrm{HR}_{\mathrm{VT} 1} / \mathrm{HR}_{\text {peak }}$ and $\mathrm{HR}_{6 \mathrm{MWT}} / \mathrm{HR}_{\text {peak }}$ were not statistically different $(81 \% \pm 5 \%$ vs. $81 \% \pm 6 \%, P=0.85)$. On average, HR.mwt's MAPE was $5.1 \%$, and SEE was $6.6 \mathrm{bpm}$. Six patients (35\%) showed a difference higher than five bpm between $\mathrm{HR}_{\mathrm{VT1}}$ and $\mathrm{HR}_{6 \mathrm{MWT}}$.

Bland-Altman analysis of agreement between $\mathrm{HR}_{\mathrm{VT1}}$ and $\mathrm{HR}_{6 \mathrm{MWT}}$ revealed a negative bias of $-0.41 \pm 6.4 \mathrm{bpm}$ and $95 \%$
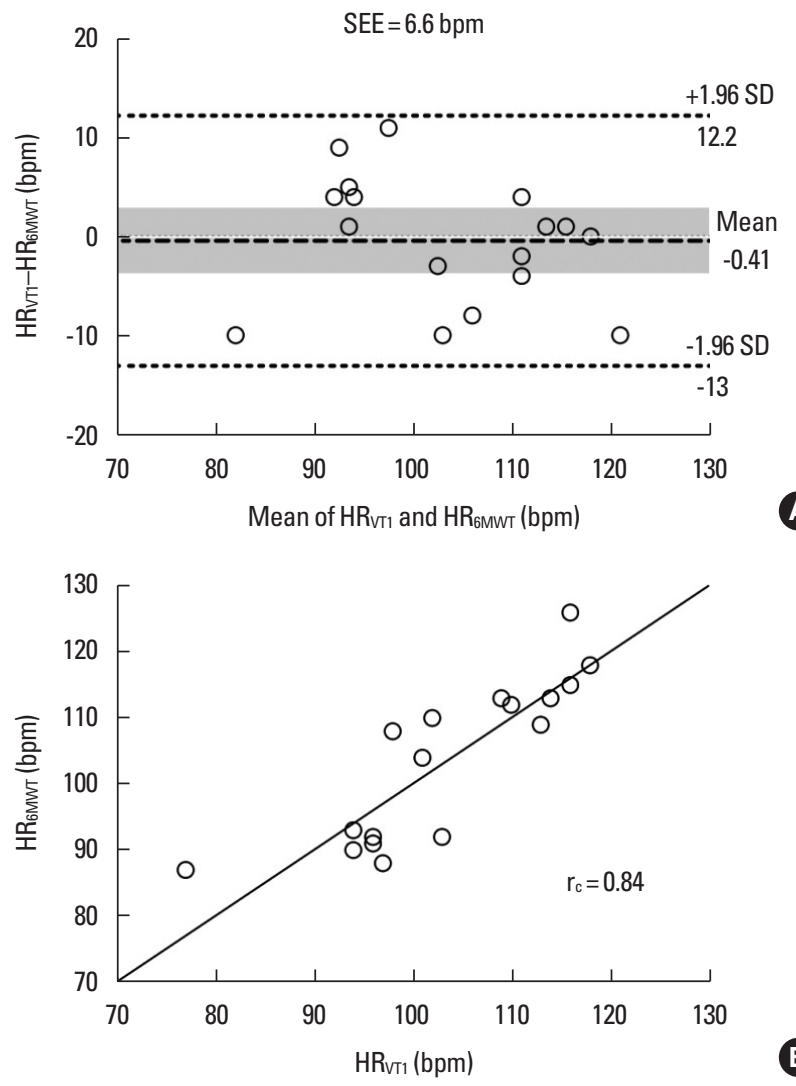

B

Fig. 1. Assessment of the agreement between the HRvт1 and the HRomwt for patients with coronary artery disease. (A) Bland-Altman plot shows the difference between $\mathrm{HR}_{\mathrm{VT} 1}$ and the HR6mwt (y-axis). The middle line represents the mean difference between methods and shaded areas present confidence interval limits for the mean ( $95 \%$ confidence interval [Cl], -3.7 to $2.9 \mathrm{bpm})$. The $95 \%$ limits of agreement ( \pm 1.96 standard deviation [SD]) fall within -13 to 12.2 bpm. (B) Concordance correlation coefficient shows agreement of HRvi1 with $\mathrm{HR}_{6 \mathrm{MWT}}\left(95 \% \mathrm{Cl}, 0.63\right.$ to 0.93). $\mathrm{HR}_{6 \mathrm{MW}}$, heart rate at 6 th min of 6-min walk test; HRvi1, heart rate at the first ventilatory threshold; SEE, standard error of estimate; rc, Lin concordance correlation coefficient. limits of agreements, -13 to $12.2 \mathrm{bpm}$ (Fig. 1A). Pearson correlation showed a high and significant association between $\mathrm{HR}_{\mathrm{VT1}}$ and $\mathrm{HR}_{\text {GMW }}(r=0.85, P<0.0001)$. In addition, Lin concordance correlation coefficient provided acceptable agreement $\left(\mathrm{r}_{\mathrm{c}}=0.84 ; 95 \%\right.$ CI, 0.63 to 0.93 ; study power analysis $=0.79)$ (Fig. 1B). These results suggest that $\mathrm{HR}_{6 \mathrm{MWT}}$ reflects $\mathrm{HR}_{\mathrm{VT} 1}$ accurately in CAD patients using $\beta$-blockers.

\section{DISCUSSION}

The main result of the present study demonstrates an acceptable agreement between $\mathrm{HR}_{\mathrm{vT1}}$ and $\mathrm{HR}_{6 \mathrm{MWT}}$ and, combined with smaller values of the MAPE and SEE, point out that is possible to use $\mathrm{HR}_{\text {gмwт }}$ as an equivalent as $\mathrm{HR}_{\mathrm{vт1}}$ to prescribe and monitor the aerobic exercise in CAD patients on $\beta$-blockers treatment.

Bland-Altman analysis results indicate the agreement between $\mathrm{HR}_{V T 1}$ and $\mathrm{HR}_{6 \mathrm{MWT}}$ values. Furthermore, the addition of SEE and MAPE to Bland-Altman analysis permitted us to measure the accuracy of agreement between $\mathrm{HR}_{\mathrm{VT} 1}$ and $\mathrm{HR}_{6 \mathrm{MWT}}$. Thus, our results showed that included patients meet the criterion of the acceptable concordance between $\mathrm{HR}_{V \mathrm{VT}}$ and $\mathrm{HR}_{6 \mathrm{MWT}}$ (SEE $\leq 7 \mathrm{bpm}$ and MAPE $\leq 5 \%$ ) (Navalta et al., 2020; Oliveira et al., 2016). Obtained data intervals are within an acceptable range for training with HR-derived methods ( $\leq 8 \mathrm{bpm}$ ) (Robergs and Landwehr, 2002). Our results agree and reinforce existent literature. Morard et al. (2015) reported agreement between $\mathrm{HR}_{\mathrm{VT1}}$ in a symptomlimited incremental CPET on a cycle ergometer and HR HMWт $_{6}$ in CAD patients with an acceptable $95 \%$ confidence interval of bias from Bland-Altman analysis (-12.3 to $8.1 \mathrm{bpm})$. Similarly, in patients with chronic heart failure, Oliveira et al. (2016) showed a high correlation between $\mathrm{HR}_{\mathrm{VT1}}$ and $\mathrm{HR}_{6 \mathrm{MWT}}(r=0.81 ; P<0.0001)$, with an acceptable SEE of $6.05 \mathrm{bpm}$. In clinical practice, our results propose the $\mathrm{HR}_{6 \mathrm{MW}}$ may be used to individualize and improve aerobic exercise prescriptions particularly to $C A D$ patients under $\beta$-blockers treatment. Thus, it is expected that the prescription of more accurate aerobic exercises may enhance the beneficial effects of aerobic training in patients undergoing a cardiac rehabilitation program.

Previous data suggest that adding $~ 30 \mathrm{bpm}$ to resting $\mathrm{HR}$ is a simple way to infer $\mathrm{HR}_{\mathrm{VT} 1}$ values when a CPET was not performed (Nemoto et al., 2019). Although our HRRvt1 values (31 \pm 11 bpm) were close to the suggested values, we believe that performing the 6MWT may be a more accurate form of exercise prescription. In addition, the $\mathrm{HRR}_{6 \mathrm{MWT}}$ was $30 \pm 8 \mathrm{bpm}$ and represents $55 \%$ of $\mathrm{HRR}_{\text {peak, }}$, a moderate aerobic exercise intensity (Hansen et al., 
2019; Pelliccia et al., 2021).

The $\mathrm{HR}_{V T 1}$ and $\mathrm{HR}_{6 \mathrm{MWT}}$ were close to $80 \%$ of the CPET $\mathrm{HR}_{\text {peak. }}$. This percentage may be considered as moderate to high intensity and is in line with the recommended aerobic training zone $(\sim 75 \%$ to $\sim 88 \% \mathrm{HR}_{\text {peak }}$ ) reported in two large cohorts of patients with CVD (Díaz-Buschmann et al., 2014; Hansen et al., 2019). Furthermore, Díaz-Buschmann et al. (2014) recommend that patients on $\beta$-blockers treatment exercise at $80 \% \mathrm{HR}_{\text {peak }}$, reinforcing the clinical applicability of our results. Additionally, clinical safety must be considered in exercise prescription in CAD patients. Thus, the founded intensity, $20 \% \mathrm{CPET} \mathrm{HR}_{\text {peak }}$, agree with recommended safety limit for aerobic exercise $\left(<90 \% \mathrm{HR}_{\text {peak }}\right)$ (Pelliccia et al., 2021).

Although Lin concordance correlation coefficient calculated study power provided acceptable agreement, is possible that this study has limitations inherent to the sample size. Furthermore, as we did not have an equal distribution between the different $\beta$-blockers used in CAD treatment the interpretation of the present results must be performed with prudence and may restrict the extrapolation of the results to another evaluated sample. Finally, as both CPET and 6MWT were performed with patients walking, our results are more accurate to this kind of aerobic exercise than the cycle ergometer, or another exercise to lower limbs aerobic exercises.

Our results suggest that the highest heart rate observed during the last $30 \mathrm{sec}$ of the 6MWT seems to be a valid tool to prescribe aerobic exercise intensity with safe at entry in a cardiac rehabilitation program for $\beta$-blockers patients. More research should be carried out to evaluate the use of $\mathrm{HR}_{6 \mathrm{MW}}$ to control the exercise intensity in the progression of the physical training program in cardiac rehabilitation.

\section{CONFLICT OF INTEREST}

No potential conflict of interest to this article was reported.

\section{ACKNOWLEDGMENTS}

The authors received no financial support for this article.

\section{REFERENCES}

Anderson L, Thompson DR, Oldridge N, Zwisler AD, Rees K, Martin N, Taylor RS. Exercise-based cardiac rehabilitation for coronary heart disease. Cochrane Database Syst Rev 2016;2016:CD001800.

Bellet RN, Adams L, Morris NR. The 6-minute walk test in outpatient car- diac rehabilitation: validity, reliability and responsiveness: a systematic review. Physiotherapy 2012;98:277-286.

Bland JM, Altman DG. Statistical methods for assessing agreement between two methods of clinical measurement. Lancet 1986;8476:307310.

Britto RR, Probst VS, de Andrade AF, Samora GA, Hernandes NA, Marinho PE, Karsten M, Pitta F, Parreira VF. Reference equations for the sixminute walk distance based on a Brazilian multicenter study. Braz J Phys Ther 2013;17:556-563.

Brubaker PH, Ross JH, Joo KC. Contemporary approaches to prescribing exercise in coronary artery disease patients. Am J Lifestyle Med 2018; 12:130-139.

Bussotti M, Apostolo A, Andreini D, Palermo P, Contini M, Agostoni P. Cardiopulmonary evidence of exercise-induced silent ischaemia. Eur J Cardiovasc Prev Rehabil 2006;13:249-253.

Carvalho T, Milani M, Ferraz AS, Silveira ADD, Herdy AH, Hossri CAC, Silva CGS, Araújo CGS, Rocco EA, Teixeira JAC, Dourado LOC, Matos LDNJ, Emed LGM, Ritt LEF, Silva MG, Santos MA, Silva MMF, Freitas OGA, Nascimento PMC, Stein R, Meneghelo RS, Serra SM. Brazilian cardiovascular rehabilitation guideline - 2020. Arq Bras Cardiol 2020;114:943-987.

Casillas JM, Gudjoncik A, Gremeaux V, Aulagne J, Besson D, Laroche D. Assessment tools for personalizing training intensity during cardiac rehabilitation: literature review and practical proposals. Ann Phys Rehabil Med 2017;60:43-49.

Casillas JM, Hannequin A, Besson D, Benaïm S, Krawcow C, Laurent Y, Gremeaux V. Walking tests during the exercise training: specific use for the cardiac rehabilitation. Ann Phys Rehabil Med 2013;56:561-575.

Chaloupka V, Elbl L, Nehyba S, Tomaskova I, Jedlicka, F. Exercise intensity prescription after myocardial infarction in patients treated with beta-blockers. J Cardiopulm Rehabil 2005;25:361-365.

Díaz-Buschmann I, Jaureguizar KV, Calero MJ, Aquino RS. Programming exercise intensity in patients on beta-blocker treatment: the importance of choosing an appropriate method. Eur J Prev Cardiol 2014;21:14741480 .

Dunlay SM, Pack QR, Thomas RJ, Killian JM, Roger VL. Participation in cardiac rehabilitation, readmissions, and death after acute myocardial infarction. Am J Med 2014;27:538-546.

Fletcher GF, Ades PA, Kligfield P, Arena R, Balady GJ, Bittner VA, Coke LA, Fleg JL, Forman DE, Gerber TC, Gulati M, Madan K, Rhodes J, Thompson PD, Williams MA; American Heart Association Exercise and Prevention Committee of the Council on Clinical Cardiology, Council on Nutrition, Physical Activity and Metabolism, Council on Cardiovascular and Stroke Nursing, and Council on Epidemiology and Prevention. Exercise standards for testing and training: a scientif- 
ic statement from the American Heart Association. Circulation 2013; 128:873-934.

Gayda M, Temfemo A, Choquet D, Ahmaïdi S. Cardiorespiratory requirements and reproducibility of the six-minute walk test in elderly patients with coronary artery disease. Arch Phys Med Rehabil 2004;85:15381543.

Gillinov S, Etiwy M, Wang R, Blackburn G, Phelan D, Gillinov AM, Desai MY. Variable accuracy of wearable heart rate monitors during aerobic exercise. Med Sci Sports Exerc 2017;49:1697-1703.

Hansen D, Abreu A, Ambrosetti M, Cornelissen V, Gevaert A, Kemps H, Laukkanen JA, Pedretti R, Simonenko M, Wilhelm M, Davos CH, Doehner W, Iliou MC, Kränkel N, Völler H, Piepoli M. Exercise intensity assessment and prescription in cardiovascular rehabilitation and beyond: why and how: a position statement from the Secondary Prevention and Rehabilitation Section of the European Association of Preventive Cardiology. Eur J Prev Cardiol 2021 Jun 2:zwab007. https:// doi.org/10.1093/eurjpc/zwab007. [Epub].

Hansen D, Bonné K, Alders T, Hermans A, Copermans K, Swinnen H, Dendale P. Exercise training intensity determination in cardiovascular rehabilitation: should the guidelines be reconsidered? Eur J Prev Cardiol 2019;26:1921-1928.

Holland AE, Spruit MA, Troosters T, Puhan MA, Pepin V, Saey D, McCormack MC, Carlin BW, Sciurba FC, Pitta F, Wagner J, Maclntyre N, Kaminsky DA, Culver BH, Revill SM, Hernandes NA, Andrianopoulos V, Camillo CA, Mitchell KE, Lee AL, Hill CJ, Singh SJ. An official European Respiratory Society/American Thoracic Society technical standard: field walking tests in chronic respiratory disease. Eur Respir J 2014;44:1428-1446.

Keteyian SJ, Brawner CA, Ehrman JK, Ivanhoe R, Boehmer JP, Abraham WT; PEERLESS-HF Trial Investigators. Reproducibility of peak oxygen uptake and other cardiopulmonary exercise parameters: implications for clinical trials and clinical practice. Chest 2010;138:950-955.

Knuuti J, Wijns W, Saraste A, Capodanno D, Barbato E, Funk-Brentano C, Prescott E, Storey RF, Deaton C, Cuisset T, Agewall S, Dickstein K, Edvardsen T, Escaned J, Gersh BJ, Svitil P, Gilard M, Hasdai D, Hatala R, Mahfound F, Masip J, Munereto C, Valgimigli M, Achenbach S, Bax JJ. ESC Scientific Document Group. 2019 ESC Guideline for the diagnosis and management of chronic coronary syndromes. Eur Heart J 2020;41:407-477.

Lin LI. A concordance correlation coefficient to evaluate reproducibility. Biometrics 1989;45:255-268.

Mezzani A, Agostoni P, Cohen-Solal A, Corrà U, Jegier A, Kouidi E, Mazic S, Meurin P, Piepoli M, Simon A, Laethem CV, Vanhees L. Standards for the use of cardiopulmonary exercise testing for the functional evaluation of cardiac patients: a report from the Exercise Physiology Sec- tion of the European Association for Cardiovascular Prevention and Rehabilitation. Eur J Cardiovasc Prev Rehabil 2009;16:249-267.

Morard MD, Bosquet L, Laroche D, Joussain C, Besson D, Deley G, Gremeaux V. Are first ventilatory threshold and 6-minute walk test heart rate interchangeable? A pilot study in healthy elderlies and cardiac patients. Ann Phys Rehabil Med 2015;58:92-97.

Navalta JW, Ramirez GG, Maxwell C, Radzak KN, McGinnis GR. Validity and reliability of three commercially available smart sports bras during treadmill walking and running. Sci Rep 2020;10:7397.

Nemoto S, Kasahara Y, Izawa KP, Watanabe S, Yoshizawa K, Takeichi N, Akashi YJ. Effect of carvedilol on heart rate response to cardiopulmonary exercise up to the anaerobic threshold in patients with subacute myocardial infarction. Heart Vessels 2019;34:957-964.

Oliveira MF, Zanussi G, Sprovieri B, Lobo DM, Mastrocolla LE, Umeda II, Sperandio PA. Alternatives to aerobic exercise prescription in patients with chronic heart failure. Arq Bras Cardiol 2016;106:97-104.

Pelliccia A, Sharma S, Gati S, Bäck M, Börjesson M, Caselli S, Collet JP, Corrado D, Drezner JA, Halle M, Hansen D, Heidbuchel H, Myers J, Niebauer J, Papadakis M, Piepoli MF, Prescott E, Roos-Hesselink JW, Graham Stuart A, Taylor RS, Thompson PD, Tiberi M, Vanhees L, Wilhelm M, ESC Scientific Document Group. 2020 ESC Guidelines on sports cardiology and exercise in patients with cardiovascular disease. Eur Heart J 2021;42:17-96.

Prado DM, Rocco EA, Silva AG, Rocco DF, Pacheco MT, Silva PF, Furlan $\mathrm{V}$. Effects of continuous vs interval exercise training on oxygen uptake efficiency slope in patients with coronary artery disease. Braz J Med Biol Res 2016;49:e4890.

Pymer S, Nichols S, Prosser J, Birkett S, Carroll S, Ingle L. Does exercise prescription based on estimated heart rate training zones exceed the ventilatory anaerobic threshold in patients with coronary heart disease undergoing usual-care cardiovascular rehabilitation? A United Kingdom perspective. Eur J Prev Cardiol 2020;27:579-589.

Robergs RA, Landwehr R. The surprising history of the "HRmax=220age" equation. J Exerc Physiol Online 2002;5:1-10.

Sarzynski MA, Rankinen T, Earnest CP, Leon AS, Rao DC, Skinner JS, Bouchard C. Measured maximal heart rates compared to commonly used age-based prediction equations in the Heritage Family Study. Am J Hum Biol 2013;25:695-701.

Tabet JY, Meurin P, Teboul F, Tartiere JM, Weber H, Renaud N, Driss AB. Determination of exercise training level in coronary artery disease patients on beta blockers. Eur J Cardiovasc Prev Rehabil 2008;15:67-72.

Tan SJJ, Allen JC, Tan SY. Determination of ideal target exercise heart rate for cardiac patients suitable for rehabilitation. Clin Cardiol 2017;40: 1008-1012.

Virani SS, Alonso A, Benjamin EJ, Bittencourt MS, Callaway CW, Carson 
AP, Chamberlain AM, Chang AR, Cheng S, Delling FN, Djousse L, Elkind MSV, Ferguson JF, Fornage M, Khan SS, Kissela BM, Knutson KL, Kwan TW, Lackland DT, Lewis TT, Lichtman JH, Longenecker CT, Loop MS, Lutsey PL, Martin SS, Matsushita K, Moran AE, Mussolino ME, Perak AM, Rosamond WD, Roth GA, Sampson UKA, Satou GM, Schroeder EB, Shah SH, Shay CM, Spartano NL, Stokes A, Tirschwell DL, VanWagner LB, Tsao CW; American Heart Association Council on Epidemiology and Prevention Statistics Committee and
Stroke Statistics Subcommittee. Heart disease and stroke statistics 2020 update: a report from the American Heart Association. Circulation 2020;141:e139-e596.

Zheng H, Luo M, Shen Y, Ma Y, Kang W. Effects of 6 months exercise training on ventricular remodelling and autonomic tone in patients with acute myocardial infarction and percutaneous coronary intervention. J Rehabil Med 2008;40:776-779. 